\title{
Donativos, préstamos y privilegios. Los mercaderes y mineros de la Ciudad de México durante la guerra anglo-española de 1779-1783
}

\footnotetext{
G U I LLERM INA DEL VALLE PAVÓN

Ciudad de México: Instituto Mora 2016 | ISBN: 978-607-9475-47-5| $228 \mathrm{pp}$.
}

DOI: $10.22380 / 20274688.456$

JAMES VLADIMIR TORRES MORENO

Georgetown University, Estados Unidos https://orcid.org/0000-0002-0841-2961

E

n México, la historia económica colonial como disciplina ha conservado su vitalidad. Los historiadores mexicanos y los mexicanistas han empezado a navegar más allá del territorio novohispano y han elaborado importantes estudios sobre el funcionamiento del sistema colonial. Tres, en mi opinión, son las coordenadas y constataciones que han surgido en los últimos años. Primero, el carácter simbiótico entre el comercio trasatlántico y el transpacífico. Es imposible seguir entendiendo a mbas rutas como un juego de suma cero entre dos sistemas comerciales distintos. Igualmente, es imposible seguir interpretando el comercio con Manila como un asunto meramente novohispano. El Pacífico suramericano, en efecto, desempeńó un papel clave en un comercio multilateral

I Una pequeña muestra de este desarrollo historiográfico puede verse en los trabajos de Bonialián; Ibarra y Hausberger; Sánchez; Tutino. 
que se expandió durante el siglo XviII. Segundo, el carácter integrado del mercado mundial de plata ha permitido entender cómo la circulación y la producción del metal blanco se veían afectadas por curvas de demanda cuyas características eran definidas por economías tan lejanas como China o India. A escala local, igualmente, el metal blanco lubricaba las ruedas del comercio entre las diversas colonias del imperio. Finalmente, el intrincado sistema de negociaciones entre las diferentes corporaciones del sistema fiscal borbónico ha llevado a matizar el carácter absolutista del imperio. En otras palabras, el soberano debía contar con el consentimiento de sus vasallos al otro lado del Atlántico para cumplir sus objetivos fiscales. El libro que se reseña a continuación constituye un importante aporte a estas tres coordenadas.

Del Valle Pavón analiza los mecanismos mediante los cuales la Corona extrajo grandes contribuciones extraordinarias de la economía novohispana para fortalecer la Real Armada y solventar los gastos bélicos durante la guerra angloespañola de 1779-1783. La historiografía se había concentrado en el flujo fiscal que desde Nueva España sostuvo la guerra en los principales teatros del Caribe. Sin embargo, la Corona optó también por una política de recaudo que incluía tres mecanismos bien enunciados en el título de la obra: donativos, préstamos y privilegios. Valle muestra que los gremios de mercaderes y mineros utilizaron los donativos para conservar y expandir privilegios otorgados por la Corona. La autora analiza cómo las redes comerciales eran sostenidas no solo a través de mecanismos privados para la reducción de los costos de transacción (redes familiares, religiosas o de paisanaje), sino también de una estrecha relación con la burocracia colonial. La autora, quizá la mejor conocedora del consulado de comerciantes mexicano durante el periodo colonial, presenta un texto bien documentado que dialoga de manera fluida con la historia política y social novohispana.

El primer capítulo estudia los donativos realizados por diversos gremios antes del inicio de la guerra en 1779 para el fortalecimiento de la armada y la construcción de un nuevo astillero en suelo novohispano. La autora pone en perspectiva su argumento al seńalar cómo el consulado de comerciantes mexicano había perdido una serie de privilegios durante las reformas borbónicas, entre ellos el derecho de recaudar las alcabalas, en I754. Durante los sesenta años que el consulado manejó la renta, se creó un fondo millonario llamado sobras de alcabalas que había sido mantenido en secreto por los diferentes priores de la organización. Una ruptura política dentro del consulado llevó al descubrimiento de dicho fondo en la década de 1770, hecho que brindó a las autoridades 
la oportunidad de obtener un cuantioso donativo para transformar su armada. Como compensación, el rey perdonó al consulado por la malversación de las sobras de alcabalas. Los mineros, por su parte, también ofrecieron un millonario donativo, esta vez con la esperanza de obtener el beneficio del establecimiento de una corporación formal que los representara, a pesar de la oposición de los comerciantes que querían conservar sus privilegios en el avío de la producción minera. Valle muestra, entonces, cómo el establecimiento del Tribunal de Minería no solo fue el resultado desinteresado de los Borbones por impulsar el sector minero, sino también el fruto de una cuidadosa negociación en medio de un inminente conflicto en el Atlántico. Finalmente, tanto comerciantes como mineros obtuvieron beneficios corporativos y también importantes títulos nobiliarios que reforzaron su prestigio político y social.

El segundo capítulo analiza la forma en que los mercaderes de México que trataban cacao de Guayaquil desde 1774 fueron beneficiados por el conflicto. La autora utiliza el estudio de caso de los comerciantes Isidro de Icaza y Francisco Yraeta para iluminar la forma en que las redes comerciales se adaptaron durante los tiempos de guerra y cómo sus conexiones con el aparato fiscal borbónico fueron fundamentales para abrir nuevos mercados. La introducción del fruto ecuatoriano se expandió luego de que en 1774 se dio una autorización a Nueva España, Guatemala, Nueva Granada y Perú para intercambiar por el Pacífico los efectos de la tierra y se redujeron sus respectivos derechos portuarios. Comerciantes como Icaza e Yraeta desplegaron una tupida red de agentes, socios y familiares que les permitió tomar ventaja de este nuevo orden. En ese contexto, la guerra de 1779 obligó a la monarquía a modificar una vez más las normas que habían restringido la actividad comercial en Hispanoamérica. En I780 se autorizó a Nueva Granada, incluida Guayaquil, a intercambiar productos por bienes europeos y asiáticos en todos los puertos de América. Este nuevo encuadre creó un nuevo comercio multilateral que incluía, además de bienes importados, mercurio de Huancavelica, cacao guayaquileño y plata andina. Comerciantes como Icaza e Yraeta obtuvieron licencias especiales gracias a sus conexiones con el virrey de turno y su activa donación de recursos para la guerra. Aquí, una vez más, se observa la relación entre donativos y privilegios que la autora analiza de manera rigurosa a lo largo del libro.

El último capítulo presenta una suerte de sociología de los comerciantes que realizaron donativos y empréstitos a la Corona durante la fase álgida de la guerra. La autora encuentra que un alto porcentaje de dichos empréstitos y donativos fue realizado por comerciantes con fuertes inversiones en unidades 
productivas agrícolas que suplían los diversos mercados urbanos y mineros del reino. Además, tenían fuertes intereses en la exportación de grana cochinilla y algodón a través del financiamiento de los corregidores y alcaldes mayores en las regiones productoras. ¿Qué privilegios obtenían estos comerciantes al apoyar los empréstitos de la Corona? Para empezar, lograron mantener en buenos términos sus contratos para suplir harinas y víveres a la Real Armada y los presidios de Barlovento. Segundo, consiguieron presionar a las autoridades virreinales para la mejora de caminos que conectaban a Veracruz y Ciudad de México con las principales regiones productoras de bienes agrícolas transables. Finalmente, lograron retrasar la aplicación en Nueva España del decreto de comercio libre que constituía uno de los últimos golpes al privilegio monopolista de los comerciantes mexicanos. En suma, la guerra abrió importantes oportunidades a gremios que se habían visto golpeados por el reformismo de la nueva dinastía.

El libro de Del Valle Pavón presenta, entonces, un decantado análisis de la estrecha relación entre redes comerciales y fisco en el marco de un sistema monárquico más consensuado de lo sostenido hasta el momento. Varios elementos, sin embargo, generan algunos interrogantes. Para empezar, la aproximación de la autora al comercio de cacao por el Pacífico privilegia el lado de la demanda. Si bien esta estrategia es entendible dado el objetivo del libro, no deja de ser sorprendente la enorme elasticidad de la oferta frente a los cambios en la reglamentación del comercio intraindiano durante los años de guerra. En teoría, la producción de cacao tendía a ser inelástica en el corto plazo, debido a que el ciclo agrícola entre sembrado y cosecha tomaba varios años. Según la autora, la importación cacaotera se amplió aún más cuando los comerciantes mexicanos ganaron licencias para exportar géneros europeos y asiáticos al sur. ¿Cómo fue posible que los cosecheros y comerciantes guayaquileńos cubrieran tan rápido la demanda novohispana? ¿Se trata, acaso, de la simple legalización de un comercio que venía floreciendo años atrás, o bien de un cambio lo suficientemente fuerte en los precios relativos para reubicar existencias?

Es importante anotar, a propósito de esto último, que los estudios sobre la economía novohispana aún están en mora de proporcionar datos duros de precios relativos para entender la estructura y el poder de mercado de los consulados a través de series de términos de intercambio y mark-ups. Lo mismo puede aducirse sobre la presunta escasez de efectos europeos en los Andes a pesar de la constante presencia de contrabandistas y, por cierto, a pesar del preludio y posterior explosión de las rebeliones andinas. Resulta interesante que en la correspondencia analizada por Del Valle no se mencionen ambos fenómenos. Finalmente, un 
dato de menor importancia pero que no deja de ser sugestivo es que la autora utiliza plata potosina y plata andina como sinónimos. En esos años, sin embargo, la mayor parte de la plata exportada hacia el Pacífico no era plata potosina, sino plata de los Andes peruanos propiamente dichos: cerro de Pasco, Hualgayoc y Cailloma. Pero esto, insistimos, son observaciones a problemas inspirados en un gran libro que sin duda marcará la agenda de futuras investigaciones.

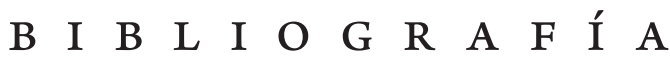

Bonialián, Mariano. El Pacífico hispanoamericano. Politica y comercio asiático en el Imperio español. Ciudad de México: Instituto Mora, 2012.

Ibarra, Antonio y Bernd Hausberger, editores. Oro y plata en le economia moderna. Ciudad de México: El Colegio de México, 2014.

Sánchez, Ernest. La imperiosa necesidad, crisis y colapso del erario de la Nueva España. Ciudad de México: Instituto Mora, 2016.

Tutino, John. The Mexican Heartland. How Communities Shaped Capitalism, a Nation, and the World. Nueva Jersey: Princeton University Press, 2017. 